\title{
Honesto y entretenido sarao (primera y segunda parte)
}

\section{Zayas y Sotomayor, María DE}

\author{
Ed. Julián Olivares, Zaragoza, Prensas Universitarias \\ de Zaragoza, 2017. 2 vols. pp. CVI + 901
}

La obligada incorporación de las novelas de María de Zayas y Sotomayor (1590-?) en los planes de estudios a ambos lados del Atlántico resulta significativa, sobre todo teniendo en cuenta que no se debe al hecho de que vengan de la pluma de una mujer, ni mucho menos a una cuestión de cuotas asociadas a los curricula universitarios. Si bien su "re-descubrimiento" para el lector y crítico actual pudo en un principio asociarse a la novedad, también es cierto que su popularidad no puede limitarse a esta consideración, ni en esta época ni en la de su aparición en la escena literaria del Barroco. Además de escribir una comedia y componer poesías varias, Zayas publicó sendas colecciones de novelas, popularmente conocidas como Novelas amorosas y ejemplares (1637) y Desengaños amorosos (1647).

Desde el momento de su publicación, las novelas gozaron de excelente recepción, siendo objeto de múltiples reediciones y traducciones, además de varias mutila- ciones y apropiaciones. Con esta nueva edición, Julián Olivares (catedrático de la Universidad de Houston) aspira a devolver las novelas al texto original, según fue concebido por su autora, lo que exige, por un lado, "una reconstrucción del texto ideal" (XIII) en cuanto al primer volumen de novelas, Honesto y entretenido sarao (1637) y, por otro, un pronunciamiento respecto al título del segundo, Parte segunda del Sarao y entretenimiento honesto (1647), en oposición al bastante más conocido de Desengaños amorosos.

La completa introducción de Olivares a las dos colecciones (un par de volúmenes) no es tanto una semblanza de la autora y su obra, lo habitual en libros de este tipo, sino que responde a la intención de acercar al lector a los fines de la construcción y producción de la narrativa de Zayas. Para ello, explica Olivares, la edición es tanto filológica como sociológica, ya que atiende a la materialidad del volumen, considerando el efecto de las legislaciones 
de la época respecto a las publicaciones de textos de ficción, así como las modificaciones a las que se ve sometido el contenido, de mano de la misma autora, por la intervención de libreros/impresores y copistas. En este sentido, el introito se abre con un breve acercamiento a la producción del libro en el Siglo de Oro para luego dar paso al estudio de la primera colección de novelas de $\mathrm{Za}$ yas desde que es entregada al librero aragonés Pedro Escuer en 1637, corregida y revisada para una segunda edición por la propia autora, y mutilada en ediciones contrahechas en 1638. Seguidamente se analizan las circunstancias que rodean a las principes de ambas colecciones en el Madrid de 1659, bajo el título de Primera y segunda parte de las Novelas amorosas y ejemplares de María de Zayas y Sotomayor. Para llegar hasta ahí, Olivares ha tomado en consideración ediciones contrahechas, no sin antes exponer los pormenores del proceso de publicación de la segunda colección, editada por Inés Casamayor (Zaragoza, 1647). Olivares explica entonces la fortuna de tiradas posteriores, haciendo hincapié en las de Agustín González de Amezúa (Novelas de 1948 y Desengaños de 1950), Alicia Illera (Desengaños de 1983) y la suya propia (Novelas de 2000).
Dada la importancia que concede al análisis de los problemas asociados con la edición de las novelas de Zayas y su énfasis en marcar la necesidad de acometer una nueva que responda o, al menos, se acerque a la voluntad original de la autora, habría sido útil evaluar críticamente al final de este apartado las ediciones de las dos partes juntas hasta la aparición de la presente, cosa que pasa casi desapercibida, al incluirse únicamente breves comentarios en notas a pie de página cuando se listan las ediciones de obras de Zayas (pongamos por caso el escolio sobre la reciente edición conjunta de la Biblioteca Castro de 2001 en la nota 11 del apartado de las "ediciones").

Esta sección sobre la historia del libro y los avatares alrededor de las novelas de Zayas se complementa con el análisis exhaustivo de, por un lado, la selección por parte de la madrileńa de los títulos de las colecciones, y, por otro, el nombre con que se refiere a los distintos relatos que las componen; un detalle que, en opinión de Olivares, no ha sido respetado por la mayoría de editores. Resulta sugestiva su propuesta de explicar la originalidad de la narradora al llamar a su primera colección Honesto y entretenido sarao, por ser un ejemplo de 
"apropiación del concepto de eutrapelia para fines feministas" (LII); sin orillar que también acuñó el término "maravilla" para referirse a sus ficciones como un modo de marcar su género sexual respecto a los escritores de aquella época, que preferirían el de "novela".

Olivares estudia detenidamente el texto y también los paratextos, concluyendo que "con los términos de maravilla y desengaños, $\mathrm{Za-}$ yas seguramente quiso designar un discurso femenino dentro del género de la novela, que defendiese a la mujer y que presentase una perspectiva femenina; y con ello rebelarse contra el dominante discurso masculino, cambiando las fórmulas y desestabilizando así la lectura de las novelas" (LXV).

Es solo al final de la introducción cuando introduce los pocos datos conocidos de María de Zayas, que hubieran ocupado un mejor espacio al principio, a modo de proemio para un lector que se acerca a estos textos por primera vez. "Osado atrevimiento" el del afanoso editor, que se arriesga a alterar el orden asumiendo, supongo, que quienes se interesen por estos volúmenes ya conocen a la madrileña, dada la popularidad a la que he aludido anteriormente. La introducción se cierra con la exposición de los criterios de edición, la nómina de las ediciones individuales y conjuntas de los relatos, seguidas de la bibliografía consultada sobre el género de la novela corta y las de Zayas en particular.

La edición propiamente dicha reserva las notas a pie de página a variantes y correcciones respecto a sus textos base: para la primera colección es el de las Novelas amorosas y ejemplares. De nuevo corretas y enmendadas por su misma Autora (Zaragoza, 1637). Para la segunda, en cambio, acude a la princeps de la Segunda parte del Sarao y Entretenimiento honesto (Zaragoza, 1647). Además de estas notas, incluye el editor otras aclaraciones de sentido que, por mínimas (apenas pasan de una docena en el segundo volumen), se podrían haber eliminado en la mayoría de los casos e incorporado al glosario final, el cual, junto con un índice de poemas, clausura dicho tomo.

Se trata, pues, de una valiosa edición de las novelas de Zayas, sobre todo para aquellos de veras atraídos por los avatares de la publicación y recepción de los impresos áureos, dado el detallado examen que firma Olivares. Más significativo resulta el que, con tal introducción, pone de manifiesto asimismo la conciencia autorial de 
Zayas respecto a sus textos, que no es respetada por libreros/editores, más entregados en la comercialidad del producto que a la intencionalidad artística de su autora.

Nieves Romero-Díaz

Mount Holyoke College 